\title{
The structure of lithium garnets: cation disorder and clustering in a new family of fast $\mathrm{Li}^{+}$conductors $\dagger$
}

\author{
Edmund J. Cussen \\ Received (in Cambridge, UK) 17th October 2005, Accepted 2nd November 2005 \\ First published as an Advance Article on the web 25th November 2005 \\ DOI: 10.1039/b514640b
}

The structure of the fast lithium-ion conducting garnets $\mathrm{Li}_{5} \mathrm{La}_{3} \mathrm{M}_{2} \mathrm{O}_{12}(\mathrm{M}=\mathrm{Ta}, \mathrm{Nb})$ reveals $\mathrm{Li}^{+}$on both tetrahedral and octahedral sites and suggests that the latter are responsible for the observed $\mathrm{Li}^{+}$mobility via a clustering mechanism.

Lithium garnets have recently been reported as potential solid electrolytes for operation in an all solid-state rechargeable lithium battery. ${ }^{1,2}$ These garnets, $\mathrm{Li}_{5} \mathrm{La}_{3} \mathrm{M}_{2} \mathrm{O}_{12}(\mathrm{M}=\mathrm{Ta}, \mathrm{Nb})$, show activated lithium ion mobility which rivals that observed in the best crystalline $\mathrm{Li}^{+}$conductors and, most importantly, the garnets are chemically stable when exposed to moisture, air and metallic lithium. Lithium-containing garnets have been known for over 35 years $^{3}$ and have been the subject of several structural reports. ${ }^{4-6}$ These compounds contain $\mathrm{La}^{3+}$ and $\mathrm{M}^{5+}$ in the usual cubic and octahedral oxide environments of the garnet structure, but are unusual in containing a greater concentration of $\mathrm{Li}^{+}$cations than can be accommodated on the tetrahedral sites commonly occupied in garnets. Instead, the $\left[\mathrm{La}_{3} \mathrm{M}_{2} \mathrm{O}_{12}\right]^{5-}$ framework must accommodate five lithium cations using some combination of the 3 tetrahedral, 6 octahedral and 3 trigonal prismatic sites which are illustrated in Fig. 1.

An understanding of the $\mathrm{Li}^{+}$transport properties requires an accurate description of the lithium sites in these compounds. However, the nature of the $\mathrm{Li}^{+}$environment in these phases has been controversial. All experimental approaches have employed $\mathrm{X}$-ray scattering and consequently provided limited information on the $\mathrm{Li}^{+}$positions. The most recent structural study ${ }^{7}$ has used a

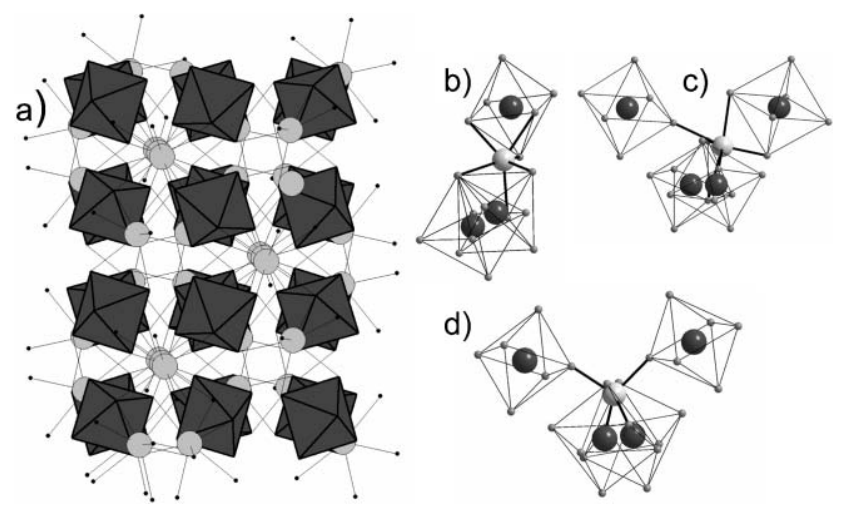

Fig. 1 (a) The $\left[\mathrm{La}_{3} \mathrm{M}_{2} \mathrm{O}_{12}\right]^{5-}$ garnet framework showing $\mathrm{MO}_{6}$ octahedral units and $\mathrm{Ln}^{3+}$ cations and potential lithium sites with (b) trigonal prismatic, (c) octahedral and (d) tetrahedral coordination.

The School of Chemistry, The University of Nottingham, Nottingham, UK NG7 2RD. E-mail: Edmund.Cussen@Nottingham.ac.uk;

Fax: +44 115951 3563; Tel: +44 1159513503

$\uparrow$ Electronic supplementary information (ESI) available: Full details of the synthetic methods, lattice energy calculations, crystal structures and Rietveld refinements. See DOI: 10.1039/b514640b bond valence approach and concluded that lithium is housed exclusively in the octahedral site which is normally vacant in the garnet structure and that the tetrahedral sites play no part in the chemistry of these phases. The results presented here show that $\mathrm{Li}^{+}$ is housed in a mixture of partially occupied sites and that clusters of mobile $\mathrm{Li}^{+}$exist within these materials.

Samples of $\mathrm{Li}_{5} \mathrm{La}_{3} \mathrm{M}_{2} \mathrm{O}_{12}$ were synthesised using standard ceramic methods from stoichiometric quantities of $\mathrm{La}_{2} \mathrm{O}_{3}$ and $\mathrm{M}_{2} \mathrm{O}_{5}$ and a $10 \%$ excess of isotopically enriched $\mathrm{Li}_{2} \mathrm{CO}_{3}$ (>99\% ${ }^{7} \mathrm{Li}$ ). X-Ray powder diffraction patterns collected from both samples contained intense peaks which could be indexed using a cubic unit cell, $a \approx 12.80 \AA$, typical of a garnet phase and a number of small peaks which suggested the presence of minority phases. In order to determine accurately the $\mathrm{Li}^{+}$ position in these garnets neutron powder diffraction data were collected over the $d$-spacing range $0.5 \leqslant d / \AA \leqslant 8.0$ using the instrument Polaris at Rutherford Appleton Laboratories, Didcot. Data were collected from both compounds at room temperature and additional data sets were collected from $\mathrm{Li}_{5} \mathrm{La}_{3} \mathrm{Ta}_{2} \mathrm{O}_{12}$ at 300 and $600{ }^{\circ} \mathrm{C}$. The room temperature data showed that the majority phase $(>94 \mathrm{wt} \%)$ in both samples exhibited systematic absences associated with the space group $I a \overline{3} d$. We found no Bragg intensity which required a reduction in the space group symmetry. Initial attempts to fit the data collected from $\mathrm{Li}_{5} \mathrm{La}_{3} \mathrm{Ta}_{2} \mathrm{O}_{12}$ used a structural model in which the lithium occupied $\%$ of the octahedrally coordinated $(48 g)$ site. However this refinement failed to converge and resulted in a poor intensity match and the large residual fit parameters shown in Table 1.

An alternative model was employed in which the lithium was disordered with occupancies of $2 / 3$ octahedral sites and $1 / 3$ tetrahedral sites $(24 d)$. This structural model improved the fit but a significant intensity mismatch remained which could be readily eliminated by refining the lithium occupancies of these two sites

Table 1 The fit parameters, lattice energies and global instability indices of a range of structural models for $\mathrm{Li}_{5} \mathrm{La}_{3} \mathrm{M}_{2} \mathrm{O}_{12}$ at room temperature

Li site occupancies

\begin{tabular}{lcrlccc}
\hline $\mathrm{Oh}$ & $\mathrm{Td}$ & $\mathrm{M}$ & $R_{\mathrm{wp}}(\%)$ & $\chi^{2}$ & Energy/eV $^{b}$ & GII/v.u. \\
\hline $5 / 6$ & 0 & $\mathrm{Ta}$ & $3.01^{a}$ & $6.937^{a}$ & - & 0.171 \\
& & $\mathrm{Nb}$ & $4.44^{a}$ & $15.69^{a}$ & 5035.6 & 0.156 \\
$2 / 3$ & $1 / 3$ & $\mathrm{Ta}$ & 2.17 & 3.593 & - & 0.151 \\
& & $\mathrm{Nb}$ & 3.07 & 7.507 & 5137.0 & 0.138 \\
$0.433(1)$ & $0.802(4)$ & $\mathrm{Ta}$ & 1.72 & 2.269 & - & 0.139 \\
$0.414(1)$ & $0.836(4)$ & $\mathrm{Nb}$ & 2.35 & 4.376 & 5119.2 & 0.129
\end{tabular}

${ }^{a}$ Failed to reach convergence. ${ }^{b}$ Calculated using GULP. No suitable potential is available for $\mathrm{Ta}^{5+} .{ }^{c}$ Global Instability Index calculated using Soft BVS. ${ }^{8}$ v.u. = valence units. 
with the constraint that the unit cell contained $5 \mathrm{Li}^{+}$per formula unit. The lithium on the $48 \mathrm{~g}$ site refined to give highly anisotropic displacement parameters indicating that the scattering intensity was disordered along a line between the opposing faces of the octahedron which are shared with neighbouring tetrahedral $\mathrm{LiO}_{4}$ units. Therefore the refinement was modified to allow the octahedrally coordinated lithium to move off the $48 \mathrm{~g}$ site and the final refinement employed a model in which the octahedral lithium was disordered with the majority of the lithium displaced away from one shared polyhedral face and towards the opposite linking face. The structural parameters are summarised in Table 2 and a fitted diffraction pattern is shown in Fig. 2.

The lithium occupancies of the tetrahedra (0.802(4)) and octahedra $(0.43(2))$ imply that face-sharing octahedral and tetrahedral pairs can be occupied simultaneously giving a mean $\mathrm{Li} \cdots \mathrm{Li}$ separation of only $1.9626(3) \AA$. The majority of lithium on the octahedral site is displaced thus splitting the $\mathrm{Li} \cdots \mathrm{Li}$ distance to $1.500(15)$ and 2.381(11) $\AA$. The latter is a physically acceptable value but the former, and the mean value, are clearly too short. The average structure does not exist within the material over the length scale of a unit cell but instead represents clustering of regions of tetrahedral and octahedral $\mathrm{Li}$, reminiscent of the structure of Lisicon. ${ }^{9}$ The size of such domains will be limited by the charge separation associated with the formation of (Td) $\left[\mathrm{Li}_{3} \mathrm{La}_{3} \mathrm{Ta}_{2} \mathrm{O}_{12}\right]^{2-}$ and $(\mathrm{Oh})\left[\mathrm{Li}_{6} \mathrm{La}_{3} \mathrm{Ta}_{2} \mathrm{O}_{12}\right]^{+}$regions. The surface of a domain containing lithium on the octahedral site must necessarily share faces with occupied tetrahedral sites in a neighbouring domain and the electrostatic repulsion associated with such a short distance is reduced by the observed displacement of some of the octahedral lithium away from one of the shared faces. The $\mathrm{LiO}_{6}$ octahedra are linked by

Table 2 Structural parameters for $\mathrm{Li}_{5} \mathrm{La}_{3} \mathrm{Ta}_{2} \mathrm{O}_{12}$ at room temperature

\begin{tabular}{|c|c|c|c|c|c|c|}
\hline & Site & Frac. & $x$ & $y$ & $z$ & $100 U_{\mathrm{eq}} / \AA^{2}$ \\
\hline $\mathrm{La}$ & $24 c$ & 1 & $1 / 8$ & 0 & $1 / 4$ & 0.71 \\
\hline $\mathrm{Ta}$ & $16 a$ & 1 & 0 & 0 & 0 & 0.43 \\
\hline $\mathrm{Li}$ & $24 d$ & $0.802(4)$ & $1 / 4$ & $7 / 8$ & 0 & $2.23(7)$ \\
\hline $\mathrm{Li}$ & $48 g$ & $0.139(8)$ & $1 / 8$ & $0.6826(8)$ & $0.5674(8)$ & $0.64(12)$ \\
\hline $\mathrm{Li}$ & $96 h$ & $0.147(9)$ & $0.0927(9)$ & $0.6840(6)$ & $0.5795(5)$ & $0.64(12)$ \\
\hline $\mathrm{O}$ & $96 h$ & 1 & $0.27965(3)$ & $0.10564(3)$ & $0.19894(3)$ & 0.88 \\
\hline
\end{tabular}

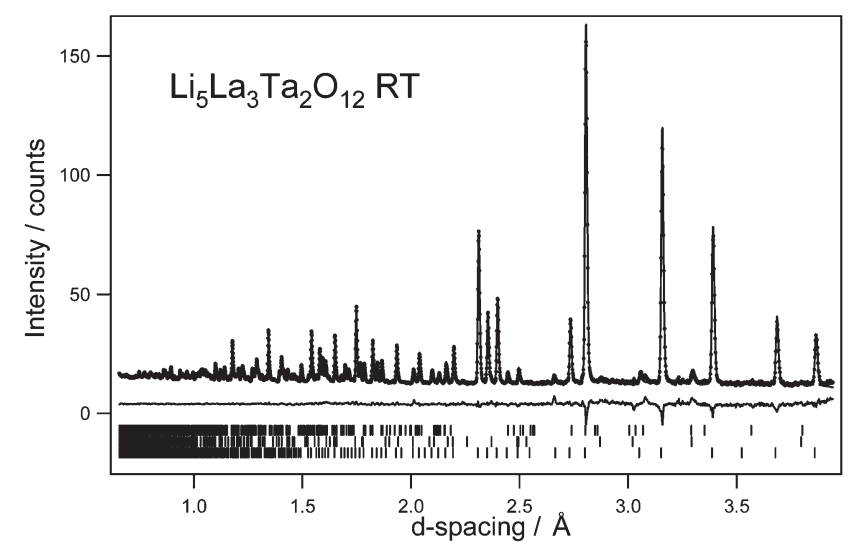

Fig. 2 Observed (dots), calculated (line) and difference neutron powder diffraction patterns collected from $\mathrm{Li}_{5} \mathrm{La}_{3} \mathrm{Ta}_{2} \mathrm{O}_{12}$ at room temperature. The lowest, middle and upper markers show allowed Bragg peaks for the garnet phase, $\mathrm{Li}_{2} \mathrm{CO}_{3}$ and $\mathrm{La}(\mathrm{OH})_{3}$ respectively.

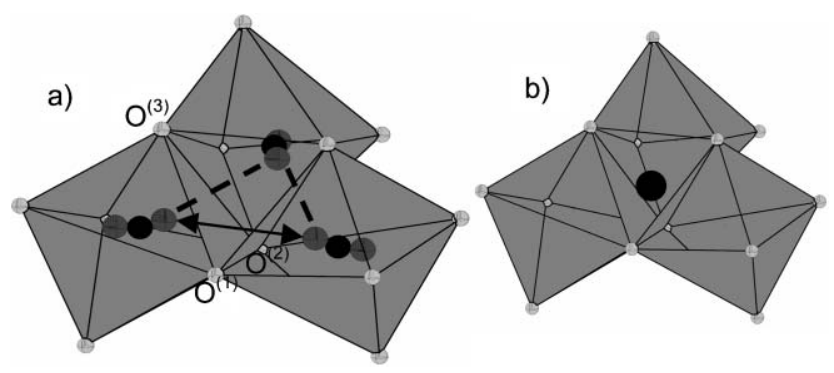

Fig. 3 Details of the lithium environments at room temperature in $\mathrm{Li}_{5} \mathrm{La}_{3} \mathrm{Ta}_{2} \mathrm{O}_{12}$ show that (a) the displaced $\mathrm{Li}^{+}$cations (light grey spheres) occupying the octahedral interstices are separated by 2.37(2) $\AA$ (dashed line) from their closest $\mathrm{Li}^{+}$neighbours and 2.92(2) $\AA$ (arrow) from other neighbours each linked by a shared octahedral edge. The $\mathrm{O}(2) \cdots \mathrm{O}(3)$ separation, 3.2368(7) $\AA$, along the edge linking the closer $\mathrm{Li}^{+}$pair is greater than the $\mathrm{O}(1) \cdots \mathrm{O}(2)$ distance, $3.0051(8) \AA$, along the edge linking the longer $\mathrm{Li}^{+}$pairs. (b) The tetrahedral interstice is at the centre of four edge-shared octahedra.

shared edges which have irregular $\mathrm{Li} \cdots \mathrm{Li}$ distances. The shortest cation separations are associated with the longest oxide-oxide distances i.e. when the $\mathrm{Li}^{+}$cations are closest the anions provide the least effective screening, as shown in Fig. 3. This suggests that $\mathrm{Li}^{+}$hopping between these sites will be relatively facile. The connectivity between these sites gives rise to a 3-dimensionally connected $\mathrm{Li}^{+}$pathway. Both the elevated temperature data sets and data collected from $\mathrm{Li}_{5} \mathrm{La}_{3} \mathrm{Nb}_{2} \mathrm{O}_{12}$ at room temperature showed the structures were not significantly different and the occupancies of the octahedral and tetrahedral $\mathrm{Li}^{+}$sites all refined to similar values in each data set.

The refined structures were used as input for a series of lattice energy calculations using the General Utility Lattice Program (GULP) $)^{10}$ and literature values for interatomic potentials. ${ }^{11,12}$ The minimised lattice energies, collected in Table 1, show that disorder of $\mathrm{Li}^{+}$over both tetrahedral and octahedral sites increases the lattice stability by $c a$. $1.7 \%$ compared to a structure which accommodates lithium wholly on the octahedral sites.

The observation of mixed $\mathrm{Li}^{+}$coordination environments and clustering shows that the lithium garnets are more complex than previously described. The structural data suggest that the $\mathrm{Li}^{+}$ mobility arises from the octahedral sites which contain a minority lithium occupancy.

The author is grateful to The Royal Society for the provision of a University Research Fellowship and to Dr R. Smith at RAL for assistance with the neutron scattering experiments and Dr J. D. Gale for providing the GULP code.

\section{Notes and references}

1 V. Thangadurai, H. Kaack and W. J. F. Weppner, J. Am. Ceram. Soc., $2003,86,437$.

2 V. Thangadurai and W. Weppner, Adv. Funct. Mater., 2005, 15, 107.

3 H. M. Kasper, Inorg. Chem., 1968, 8, 1000.

4 D. Mazza, Mater. Lett., 1988, 7, 205.

5 J. Isasi, M. L. Veiga, R. Saez-Puche, A. Jerez and C. Pico, J. Alloys Compd., 1991, 177, 251.

6 H. Hyooma and K. Hayashi, Mater. Res. Bull., 1988, 23, 1399.

7 V.Thangadurai, S. Adams and W. Weppner, Chem. Mater., 2004, 16, 2998.

8 S. Adams, Acta Crystallogr., Sect. B, 2001, 57, 278.

9 I. Abrahams, P. G. Bruce, W. I. F. David and A. R. West, Acta Crystallogr., Sect. B, 1989, 45, 457.

10 J. D. Gale, J. Chem. Soc., Faraday Trans., 1997, 93, 629.

11 T. S. Bush, J. D. Gale, C. R. A. Catlow and P. D. Battle, J. Mater. Chem., 1994, 4, 1765.

12 R. Jackson and M. E. G. Valerio, J. Phys.: Condens. Matter, 2005, 17, 837. 